\title{
Identification of a novel mammalian post-translational modification, phosphocholine, on placental secretory polypeptides
}

\author{
Tristan M Lovell, Russell J Woods, David J Butlin, Kerensa J Brayley, Isaac T Manyonda', \\ Jackie Jarvis ${ }^{2}$, Steve Howell ${ }^{3}$ and Philip J Lowry \\ School of Biological Sciences, University of Reading, Reading RG6 6AJ, UK \\ ${ }^{1}$ Department of Obstetrics and Gynaecology, St George's Hospital, London SW17 OQT, UK \\ ${ }^{2}$ Bruker Daltonics Limited, Coventry CV4 9GH, UK \\ ${ }^{3}$ National Institute for Medical Research, Mill Hill, London NW7 1AA, UK \\ (Correspondence should be addressed to P J Lowry; Email: p.j.lowry@ reading.ac.uk)
}

\begin{abstract}
Placental neurokinin B appears to be post-translationally modified by phosphocholine (PC) attached to the aspartyl side chain at residue 4 of the mature peptide. Corticotrophin releasing factor (CRF) was found to be expressed by the rat placenta with the main secreted forms being phosphocholinated proCRF $+/$ - one or two polysaccharide moieties. A combination of high-pressure liquid chromatography (HPLC) and two-site immunometric analysis suggested that PC was also attached to the placental precursors of adrenocorticotrophin, hemokinin, activin and follistatin. However, the fully processed forms of rat placental activin and CRF were free of PC. Formerly, the parasitic filarial nematodes have used $\mathrm{PC}$ as a post-translational modification, attached via the polysaccharide moiety of certain secretory glycoproteins to attenuate the host immune system allowing parasite survival, but it is the PC group itself which endows the carrier with the biological activity. The fact that treatment of proCRF peptides with phospholipase $\mathrm{C}$ but not endoglycosidase destroyed PC immunoreactivity suggested a simpler mode of attachment of PC to placental peptides than that used by nematodes. Thus, it is possible that by analogy the placenta uses its secreted phosphocholinated hormones to modulate the mother's immune system and help protect the placenta from rejection.
\end{abstract}

Journal of Molecular Endocrinology (2007) 39, 189-198

\section{Introduction}

The placenta is known to control the mother's metabolism for the benefit of the foetus often, as in pre-eclampsia, to the mother's detriment. In this, it is comparable to parasites which have also evolved sophisticated mechanisms to control the host, including manipulation of immune surveillance allowing parasitic survival (Harnett \& Harnett 1993). The fact that the developing placenta is capable of producing significant concentrations of chorionic gonadotrophin (Brody \& Carlstrom 1962) and placental lactogen (Kaplan et al. 1968, Saxena et al. 1968), is a testament to its ability to act as an efficient endocrine organ, but although the mRNAs of many other peptide and protein hormones can be found in placental extracts, there are only a few reports of significant concentrations of translated products in maternal blood (for review, see Krieger 1982).

Two good examples are the neuropeptides corticotrophin releasing factor (CRF) and neurokinin B (NKB), both of which are synthesised and secreted by the human placenta reaching nanomolar concentrations in maternal blood in certain pathological conditions, such as pre-eclampsia (NKB (Page et al. 2000), CRF (Campbell et al. 1987, Florio et al. 2004)) and pre-term labour (CRF (Campbell et al. 1987, Mclean et al. 1995)). Formerly, the low abundance of these neuropeptide hormones found in placental tissue extracts has made their complete chemical characterisation difficult, but now modern mass spectrometrical technology should have made this achievable.

During an attempt to isolate and characterise human NKB from term human placentae (using preparative C3 HPLC, gel filtration and microbore C8 HPLC), we detected a number of abundant co-purifying substances in the molecular mass range $900-1300 \mathrm{kDa}$ (cf. brain NKB $1209 \mathrm{kDa}$ ) that, when subjected to TOF-TOF (time of flight-time of flight) mass spectrometry (Bruker UltraFLEX, Bruker Daltonics Limited, Coventry, UK) fragmented to strong mass ion signals of 184 and $104 \mathrm{kDa}$, consistent with those of phosphocholine (PC) and choline respectively. As these PC-containing substances did not just coincide with the immunoreactive NKB peak fractions in the final purification step, we concluded that 
there were other PC-associated peptides present which may have been formed during autolysis of other PC-containing peptides/proteins in the term human placenta. In mammals, PC is normally attached to glycerol as part of phosphatidylcholine and constitutes an important part of the membrane complex (Vance 1990). However, protein-/peptide-bound PC has been found only as part of complex N-linked polysaccharide post-translational modification (PTM) found on certain (parasitic) filarial nematode secretory proteins which are used to attenuate the host immune response (Haslam $e t$ $a l .1997)$. The immunomodulatory properties of this PC group relate to its capacity to inhibit B- and T-cell activation and promote a Th2-type rather than a Th1type immune response (Harnett et al. 2003), which are generally associated with protection. Indeed, helminth nematode infection has the capacity to promote allograft survival through the induction of type 2 immunity development and inhibition of allospecific cytotoxic T-lymphocyte activity (Liwski et al. 2000). The carrier protein and the mode of attachment of PC does not appear to be important in this respect, as PC coupled directly to BSA can mimic the attenuating effect on the immune system (Harnett \& Harnett 1993). This paper describes the discovery of this novel mammalian PTM attached to a number of placental hormones and reviews the implications in human physiology and disease. Although it was generally accepted that CRF expression was confined to primate placentae (Robinson et al. 1989), another unexpected finding of this study was the significant concentrations of immunoreactive CRF and proCRF peptides in rat placental and plasma extracts.

\section{Materials and methods}

\section{Rationale behind the use of affinity purified antibodies}

The reason for generating in-house high affinity purified immunoglobulins is that their use minimises the chance of non-specific cross-reactions. In PAGE immunoblots, we compared the results between immunoglobulin Gs (IgGs) affinity purified on different epitopes to counteract any possibility of false positives and facilitate identification. The two-site immunoassay technique which needs both epitopes to be occupied in the analyte to give a signal is thus even less prone to giving nonspecific reactions and relies on an equivalent amount of each IgG binding in a stoichiometric reaction to the relative epitope (the initial reaction mixture contains both IgGs in excess). In the immunometric assay, interference in complex formation gives rise to negative readings, in contrast to classical immunoassays where perturbation of the equilibrium will give rise to false positives. Although we did not have any PC-containing neuropeptides to use as standards in our immunometric assays, it would be expected that the stoichiometry would ensure similar ELISA readouts as the preparation of all affinity IgGs was similar. The coincidence of readouts around chromatographic peaks when comparing the twosite peptide/peptide immunometric assay results with the respective peptide/PC results is evidence that the technology is providing the expected specificity. Proximity of bulky N-linked polysaccharide moieties attached near antibody epitopes (either peptide or PC) would stereochemically hinder the binding of the relevant IgG. Multiple PC PTMs attached to the same peptide backbone would result in an equivalent amount of bound biotinylated anti-PC IgG thus increasing the final signal respectively in an anti-PC/anti-peptide assay over the result from an anti-peptide/anti-peptide immunoassay. The anti-PC/anti-PC two-site assay would only detect peptides/proteins containing more than one PC PTM available for binding the anti-PC IgG.

\section{Antisera production and IgG affinity purification}

Apart from the commercial RIA used in our original NKB study (Page et al. 2000) all other assays were generated in house.

$\mathrm{NKB}(1-5)-$ Cys- $\mathrm{NH}_{2}$ and hemokinin (1-5)-Cys- $\mathrm{NH}_{2}$ were coupled to 'purified protein derivative' (Vet Labs Agency, Surrey, UK) which had been derivatised with 4-maleimidobutyric acid $N$-hydroxysuccinimide ester (Sigma). NKB (6-10) was coupled to the same protein with glutaraldehyde. PC-KLH was purchased from Biosearch Tech Inc., Novato, CA, USA. Antisera were raised in sheep by monthly injections of immunogen $(100 \mu \mathrm{g})$ emulsified in Freund's adjuvant.

Anti-PC IgG was affinity purified on $p$-aminophenylphosphorylcholine solid phase (Perbio Science UK Ltd, Cramlington, Northumberland), anti-hemokinin(1-5), anti-NKB (1-5) were affinity purified on the respective peptide coupled through the C-terminal cysteine to iodoacetyl gel (Perbio Science UK Ltd). AntiNKB(6-10) sheep immunoglobulins were affinity purified on the same peptide coupled to cyanogen bromide-activated Sepharose. Bound antibodies were eluted using $50 \mathrm{mM}$ sodium acetate/formate buffers containing $20 \%(\mathrm{v} / \mathrm{v})$ acetonitrile with a $\mathrm{pH}$ gradient from 6 to 3 . Acetonitrile was removed using a vacuum concentrator. The anti-inhibin/activin $\beta A$-subunit antibodies (Knight et al. 1996) and the production of anti-proCRF (1-21) and anti-CRF(21-41) IgGs have been described previously (Sanderson et al. 2000).

\section{Acid extraction of and purification of placental peptides}

Human term placentae were obtained with consent after full explanation of the purpose and nature of all 
procedures used. Rat brain and placentae (Day 20 of pregnancy) were obtained from time-mated Wistar rats (Charles River UK Limited, Kent, UK), caged and maintained as required by the United Kingdom Animals (Scientific Procedures) Act 1986. Tissues were rinsed in saline and homogenised at $4{ }^{\circ} \mathrm{C}$ in ten volumes $(\mathrm{w} / \mathrm{v})$ of acid extraction buffer $(1 \mathrm{M} \mathrm{HCl}$ containing $5 \%(\mathrm{v} / \mathrm{v})$ formic acid, $1 \%(\mathrm{w} / \mathrm{v}) \mathrm{NaCl}, 1 \%$ $(\mathrm{v} / \mathrm{v})$ trifluoroacetic acid (TFA) and $0.1 \%(\mathrm{v} / \mathrm{v})$ $\beta$-mercaptoethanol). After centrifugation $(34500 \mathrm{~g}$, $4{ }^{\circ} \mathrm{C}$ ), the supernatant was loaded onto a Sep-Pak C18 cartridge (Waters, Milford, MA, USA) and washed with $0.1 \%(\mathrm{v} / \mathrm{v})$ TFA. Peptides were eluted with $0.1 \%(\mathrm{v} / \mathrm{v})$ TFA containing $80 \%(\mathrm{v} / \mathrm{v})$ acetonitrile and then dried in a vacuum centrifuge with $1 \mathrm{mg}$ mannitol. Peptides were resuspended in water before use.

A Sep-Pak extract equivalent to $100 \mathrm{~g}$ rat placentae or whole human placenta was subjected to preparative reverse phase HPLC using a Hi-bore RP-318 C3 $10 \mathrm{~mm} \times 250 \mathrm{~mm}$ column (Bio-Rad). Peptides were eluted with a gradient of $10-60 \%$ aqueous acetonitrile $/ 0.1 \%(\mathrm{v} / \mathrm{v})$ TFA at a flow rate of $2.5 \mathrm{ml} / \mathrm{min}$. Fractions $(0.5 \mathrm{~min})$ were dried by vacuum centrifuge with $1 \mathrm{mg}$ mannitol before resuspending in $100 \mu \mathrm{l}$ of $20 \mathrm{mM} \mathrm{HCl}$. Samples were freeze-dried over $\mathrm{NaOH}$ pellets (to exchange protein $\mathrm{TFA}^{-}$for $\mathrm{Cl}^{-}$to render them more water soluble) and then resuspended in $50 \mu \mathrm{l}$ nuclease/protease-free water.

Placental NKB was further purified by gel filtration on Superdex-peptide column (Amersham) equilibrated with $0.1 \%(\mathrm{v} / \mathrm{v}) \mathrm{TFA} / 20 \%(\mathrm{v} / \mathrm{v})$ acetonitrile at a flow rate of $0.25 \mathrm{ml} / \mathrm{min}$, followed by microbore HPLC $(1 \times 150 \mathrm{~mm}$ C8 Vydac column run at $70 \mu \mathrm{l} / \mathrm{min}$ with a gradient $0.1 \%(\mathrm{v} / \mathrm{v}) \mathrm{TFA} / 10 \%(\mathrm{v} / \mathrm{v})$ acetonitrile to $0.1 \% \mathrm{TFA}(\mathrm{v} / \mathrm{v}) / 60 \%(\mathrm{v} / \mathrm{v})$ acetonitrile). Fractions $(\sim 40 \mu \mathrm{l})$ were hand collected.

\section{Digestion with Asp-N protease}

Purified NKB or synthetic NKB was diluted into $500 \mu \mathrm{l}$ assay buffer (0.05 M phosphate buffer ( $\mathrm{pH} 7.5) 0.1 \%$ BSA $0.02 \%$ thiomerosal) to a concentration of $1 \mathrm{ng} / \mathrm{ml}$. After addition of $1 \mathrm{U}$ Asp-N endoprotease (Calbiochem Endoprotease Asp-N excision grade Pseudomonas fragi), the mixture was incubated for $2 \mathrm{~h}$ at $37^{\circ} \mathrm{C}$. The mixtures were then assayed in duplicate in the two-site NKB immunometric assay (see below).

\section{ELISA protocol}

Affinity purified IgG fractions were either coated directly $\left(200 \mathrm{ng} / 100 \mu \mathrm{l}\right.$ of $0.1 \mathrm{M} \mathrm{NaCO}_{3}$ per well incubated overnight $(\mathrm{o} / \mathrm{n})$ on Nunc-maxisorb immunoplate F96; the capture antibody) or biotinylated using biotinamido-caproate- $n$-hydroxyl succinamide ester; the second site antibody. Before use, coated plates were blocked o/n (50 $\mathrm{mM} \mathrm{PO}_{4}$ buffer ( $\left.\mathrm{pH} 7.4\right)$, $5 \%(\mathrm{w} / \mathrm{v})$ BSA and $0.02 \%(\mathrm{w} / \mathrm{v})$ thimerosal $)$ and washed $(50 \mathrm{mM}$ Tris-buffered saline $(\mathrm{pH} \quad 7.5)$ containing $0.05 \%(\mathrm{v} / \mathrm{v})$ Tween 20 and $0.02 \%(\mathrm{w} / \mathrm{v})$ thimerosal (TBST)). After incubating $\mathrm{o} / \mathrm{n}$ with $100 \mu \mathrm{l}$ sample diluted in assay buffer $\left(50 \mathrm{mM} \mathrm{PO}_{4}\right.$ buffer $(\mathrm{pH}$ $7.4), 0.5 \%(\mathrm{w} / \mathrm{v}) \mathrm{BSA}$ and $0.02 \%(\mathrm{w} / \mathrm{v})$ thimerosal), the plates were washed and then incubated with the secondsite biotinylated antibody for $4 \mathrm{~h}$ at RT (100 ng/well). After washing, streptavidin-linked alkaline phosphatase (Sigma) was added (100 $\mu \mathrm{l} /$ well; 1:10 $000 \mathrm{in} \mathrm{TBST}$ ) and incubated for $2 \mathrm{~h}$ at RT. Following washing, bound alkaline phosphatase was detected using para-nitrophenyl phosphate ( $200 \mu \mathrm{l} /$ well; Sigma). After $20 \mathrm{~min}$ at RT the reaction was stopped by addition of $2 \mathrm{M} \mathrm{NaOH}$ ( $50 \mu \mathrm{l} /$ well). Absorbance was read at $405 \mathrm{~nm}$ (reference wavelength $650 \mathrm{~nm}$ ) using a microplate reader (Emax; Molecular Devices Ltd, Berks, UK). proCRF immunometric assay used antibodies to extreme $\mathrm{N}$ - and C-terminal epitopes in the 161 residue precursor, antiproCRF(1-21) and anti-CRF(21-41) or proCRF 140-161, the NKB/NKB assay used an anti$\mathrm{NKB}(1-5))$ /anti-NKB(6-10) combination, activin A, as reported previously (Knight et al. 1996) and the hemokinin assay used anti-HK(1-5)/anti- NKB (6-10).

\section{Anti-PC western immunoblot}

Random HPLC fractions from the C3 HPLC of the rat placental extract were resolved by SDS-gel electrophoresis on $16 \%$ polyacrylamide tris/tricine gels in reducing conditions and transferred by electroblotting on to polyvinylidene diflouride (PVDF). Membranes were blocked overnight in TBST containing $4 \%$ BSA. Immunoblotting was performed by incubating the membrane with affinity purified biotinylated anti-PC-antibody $(50 \mathrm{ng} / \mathrm{ml}$ in TBST containing $0.5 \%(\mathrm{w} / \mathrm{v})$ BSA). Biotinylated antibodies were localised using steptavidin-HRP and visualised with Amersham Pharmacia Biotech ECL Western blotting Detection System in accordance with the manufacturer's instructions.

\section{Preparation of anti-CRF Sepharose and purification of CRF containing peptides}

Affinity purified anti-CRF (21-41) IgG was coupled to cyanogen bromide activated Sepharose $(8 \mathrm{mg}$ $\mathrm{IgG} / 1.5 \mathrm{ml}$ Sepharose gel per column) in $100 \mathrm{mM}$ HEPES buffer ( $\mathrm{pH} 8)$, mixed o/n at $4{ }^{\circ} \mathrm{C}$, blocked by the addition of $1 \mathrm{M}$ ethanolamine $/ \mathrm{HCl}$ and then washed in $100 \mathrm{mM}$ HEPES buffer $(\mathrm{pH} 8)$.

Plasma or placenta were obtained from pregnant rats (Day 20 of pregnancy; $n=10$ per group). Plasma was pooled $(17 \mathrm{ml})$ and placental tissue was acidified 
and Sep-Pak extracted, and subjected to reverse phase HPLC as described above before being pooled. Separate plasma and placenta pools were made up to a final concentration of $100 \mathrm{mM}$ HEPES ( $\mathrm{pH} 8$ ) before being mixed separately with $1.5 \mathrm{ml}$ anti-CRF IgG Sepharose $\mathrm{o} / \mathrm{n}$ at $4{ }^{\circ} \mathrm{C}$. Each $\mathrm{IgG} /$ Sepharose gel preparation was packed separately into columns and washed with $30 \mathrm{ml}$ of $100 \mathrm{mM}$ HEPES $/ 0.01 \%$ (v/v) triton X-100, $30 \mathrm{ml}$ of $100 \mathrm{mM}$ HEPES, $6 \mathrm{ml}$ of $0.5 \mathrm{M}$ ammonium acetate containing $20 \%(\mathrm{v} / \mathrm{v})$ acetonitrile (high salt wash) and $6 \mathrm{ml}$ water $/ 20 \%(\mathrm{v} / \mathrm{v})$ acetonitrile. Bound CRF-containing peptides were eluted in $0.1 \%$ (v/v) formic acid/20\% (v/v) acetonitrile (1 ml fractions). Acetonitrile was then removed using a vacuum centrifuge. The eluted CRF peptides were resolved by SDS-PAGE and immunoblotted as described in anti-PC western immunoblot utilising affinity purified biotinylated anti-PC, anti-CRF or anti-proCRF antibodies $(50 \mathrm{ng} / \mathrm{ml}$ in TBST containing $0.5 \%(\mathrm{w} / \mathrm{v}) \mathrm{BSA})$.

\section{Enzymatic treatment of placental pro-CRF and activin A ( $\beta A-\beta A$ dimer)}

In Fig. 4, fractions 36-37 (peak one) and fractions 41-43 (peak two) containing proCRF-PC and pro- $\beta$ APC immunoreactivity were pooled individually. To wells of anti-proCRF (or anti- $\beta$ A)-coated plates, $100 \mu \mathrm{l}$ sample was added and incubated overnight. After washing, plate wells were subjected to overnight digestion at $37^{\circ} \mathrm{C}$ with either phospholipase $\mathrm{C}$ (Bacillus cereus PLC; Calbiochem) at 3 units/well in $10 \mathrm{mM}$ Tris (pH 8) containing $150 \mathrm{mM} \mathrm{NaCl}, 5 \mathrm{mM} \mathrm{CaCl}_{2}, 0.1 \%$ $(\mathrm{v} / \mathrm{v})$ Triton X-100 and $0.05 \%(\mathrm{v} / \mathrm{v})$ BSA or with an enzymatic protein deglycosylation cocktail (Sigma; E_DEGLY; equivalent to $0.2 \mu \mathrm{l}$ each enzyme per well in $50 \mathrm{mM}$ phosphate buffer containing $0.1 \%(\mathrm{w} / \mathrm{v})$ SDS, $50 \mathrm{mM} \beta$-mercaptoethanol and $0.75 \%$ (v/v) Triton $\mathrm{X}-100)$. Plates were then washed and treated as Day 2 of the anti-proCRF/anti-PC ELISA (or anti- $\beta A /$ anti-PC ELISA). Anti-proCRF/anti-CRF and activin A ELISAs were run as controls for proteolytic interference.

\section{Results}

When human placental extracts were submitted to gel filtration (Superdex-peptide) and the resulting fractions were monitored with the NKB RIA used in our earlier study (Page et al. 2000), the immunoreactivity consistently eluted as a single peak with a Kav of 0.45 when compared with 0.48 for synthetic/brain NKB suggesting that the placental form was slightly larger than that found in neural tissue. Successive purification of this placental NKB by preparative C3 HPLC, gel filtration and finally microbore C8 HPLC resulted in peak fractions with absorbance readings in the
$\mathrm{NKB} / \mathrm{NKB}$ 'two-site' immunometric assay of $0.30,0.73$ and 0.39 when compared with those of $0.27,0.71$ and 0.38 in the $\mathrm{PC} / \mathrm{NKB}$ 'two-site' immunometric assay. The close coincidence of the results in each assay of such purified material would suggest that the same peptide is being measured in both assays and thus the small increase in molecular size of placental NKB appears to be caused by PTM by PC. The immunoreactivity of this same purified placental NKB (monitored by the NKB/ $\mathrm{NKB}$ 'two-site' assay) was resistant ( $11 \%$ loss after $2 \mathrm{~h}$ ) to proteolytic digestion with AspN, whereas the immunoreactivity of synthetic NKB was as expected largely destroyed ( $75 \%$ loss) by the same treatment. As AspN cuts peptide chains before aspartyl residues and the $\mathrm{N}$-terminal NKB IgG used in this assay had been affinity purified on $\operatorname{NKB}(1-3)$ attached to solid phase, this result suggests that the $\mathrm{PC}$ modification was on the side group of the aspartyl residue at position 4 of placental NKB (Asp-Met-His-Asp ${ }^{(\sim \text { PC)}-P h e-P h e-V a l-G l y-L e u-M e t-~}$ $\mathrm{NH}_{2}$ ) and was responsible for reducing the activity of the protease at its target residue by altering the chemical character of the side chain.

The PC modification also seemed to be present on proCRF. Mature rat proCRF is a 161 residue peptide (human proCRF is a 170mer) with CRF comprising the last 41 residues (121-161 in the rat and 130-170 in human proCRF). Figure $1 a$ shows the results of several 'two-site' immunometric assays of Sep-Pak extracts of human and rat placentae (Fig. $1 b$ depicts the epitopes in proCRF of the antibodies used in this study). Despite the previous report of the absence of CRF mRNA in the rat placenta (Robinson et al. 1989) there was clear evidence of immunoreactive full-length proCRF detected by the anti-proCRF (1-21)/anti-CRF two-site assay in rat placental extracts. A strong signal was also found in the two-site immunometric assay using an anti-proCRF(1-21) IgG combined with the anti-PC IgG in both human and rat placental extracts suggesting that there was more than one PC attached to proCRF. As the anti-proCRF/anti-PC assay did not appear to detect significant reactivity in brain extracts, this suggests that PC is attached as a PTM to proCRF predominantly in the placenta. The strong positive result with the anti-PC/anti-PC assay suggests that there may be other placental products than proCRF that contain more than one PC as a PTM. There was slight evidence, however, for other phosphocholinated material in rat brain extracts. Because the presence of CRF immunoreactivity in the rat placenta was unexpected we decided to explore it further.

The results of Sep-Pak rat placental and plasma extracts (after affinity purification on solid phase antiCRF IgG) submitted to SDS-PAGE and immunoblotted with affinity purified anti-CRF, anti-proCRF (1-21) and anti-PC IgGs are shown in Fig. 2. As all these materials should carry the CRF epitope, the only CRF-immunoreactive band which did not cross-react with the anti-PC 


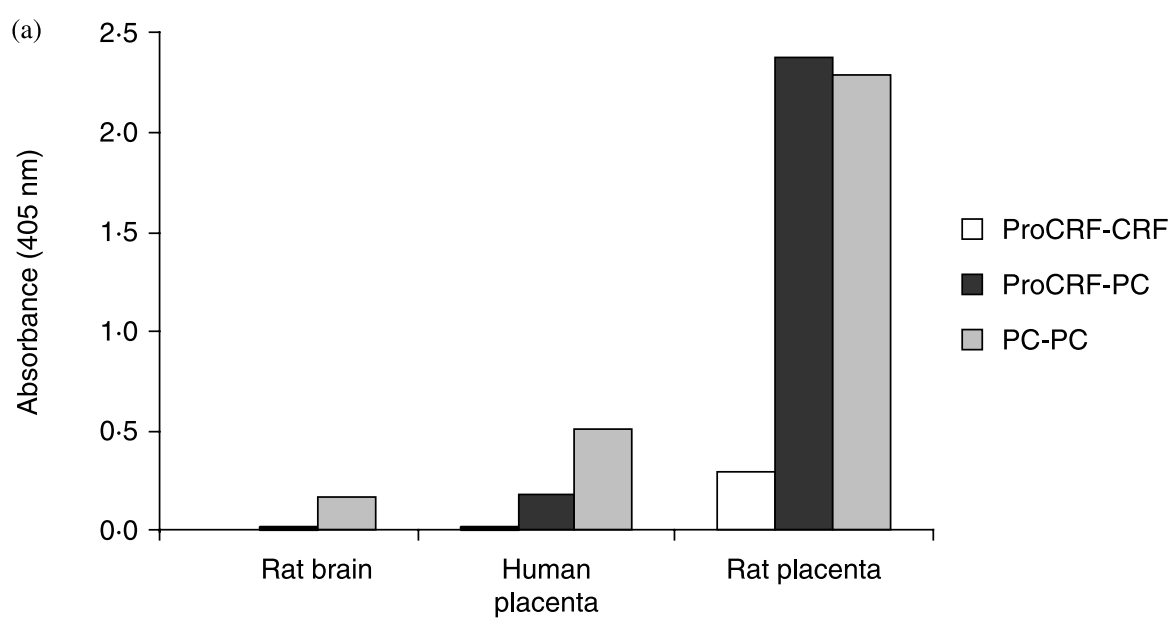

(b)

Anti-PC IgG

Anti-PC IgG

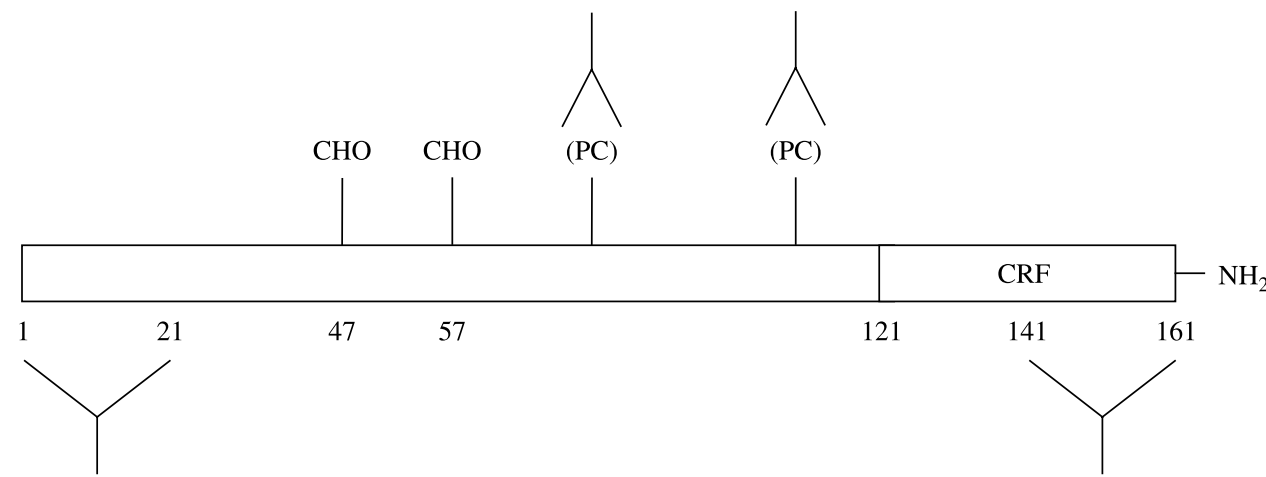

Anti-proCRF IgG

Anti-CRF IgG

Figure 1 (a) Detection of proCRF, PC-containing proCRF and PC/PC-containing material in rat (day 20 of pregnancy) and human (term) placental and rat brain extracts. Open histograms are the ELISA results from the proCRF/CRF two-site immunometric assay, black proCRF/PC assay and grey PC/PC assay. Data plotted are the means of duplicate determinations. (b) Diagram depicts the structure of proCRF and the epitopes of the antibodies used in this study.

IgG (or anti-proCRF) was the $4.5 \mathrm{kDa}$ band representing mature CRF. When the same starting extract was submitted to gel filtration on Superdex 75 this CRF band eluted in the same position as synthetic CRF.

There is clear evidence for a number of large molecular weight proCRF bands in both placenta and plasma immunoblots which also reacted with the anti-PC IgG. A $15 \mathrm{kDa}$ band is present in all three tracks of both placental and plasma extract immunoblots. As this $15 \mathrm{kDa}$ band cross-reacts with affinity purified IgGs to the extreme $\mathrm{N}$ - and C-terminal eptitopes of mature proCRF (residues 1-21 and 161-181 see Fig. 1b), and also with the anti-PC IgG, it must represent mature (nonglycosylated) phosphocholinated rat proCRF. It is difficult to predict what effect a highly charged zwitterionic group such as PC has on the mobility in SDS-PAGE, but as mature proCRF has a predicted molecular mass of $17.8 \mathrm{kDa}$ it would appear that this particular propeptide

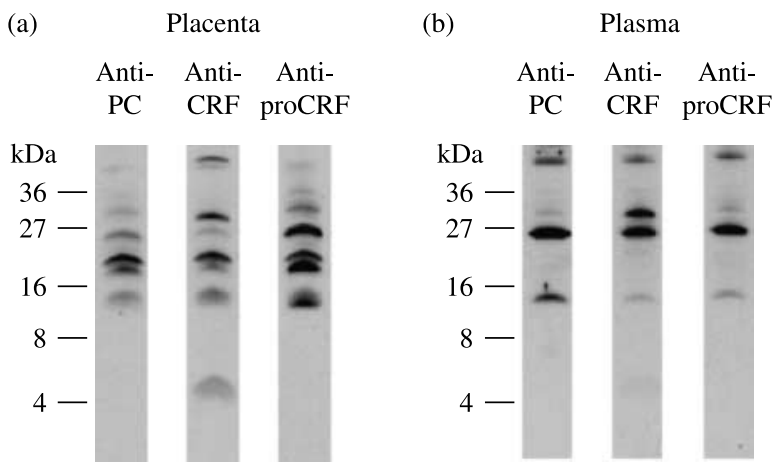

Figure 2 Affinity purified rat (a) placenta and (b) plasma CRFimmunoreactive material subjected to SDS-PAGE. Western tracks were immunobloted separately with either anti-PC-, antiCRF- or anti-proCRF- IgGs (Fig. 1b). 
sequence naturally runs faster. There is evidence for a slightly faster running band than the $15 \mathrm{kDa}$ band in the anti-CRF and anti-proCRF tracks in the placental extract blots (Fig. 2a), which is not present in the anti-PC track suggesting that PC modification may have a small effect on the SDS-PAGE electromobility. The pattern of bands in the placental extract immunoblot also appears to be more complex suggesting the presence of other processing intermediates which are not present in rat plasma where the pattern observed would be representative of the final secreted forms. As rat proCRF contains two consensus motifs for N-linked polysaccharide moiety attachment (at asparaginyl residues 47 and 57) and the $15 \mathrm{kDa}$ band represents non-glycosylated phophocholinated proCRF, any larger molecular weight band would be caused by glycosylation. In the plasma extract immunoblot (Fig. 2b), the reduced intensity of the $30 \mathrm{kDa}$ vs $25 \mathrm{kDa}$ bands in the anti-proCRF(1-21) and anti-PC tracks when compared with the anti-CRF track suggests that the proximity of two bulky polysaccharide moieties (attached at residues 47 and 57) has a greater steric hindrance effect on antibody binding to the more proximate proCRF (1-21) and PC epitopes than to the CRF epitope present at the extreme C-terminal of proCRF (residues 141-161). The fact that all secreted proCRF bands are PC immunoreactive suggests that phophocholination modification in the placenta is complete, whereas glycosylation is only partial.

As a number of other neuropeptide antibody/PC antibody combination peptide/peptide peptide/PC assays for precursor hormones, such as proNKB, prohemokinin, proopiomelanocortin, follistatin and pro-activin $\mathrm{A}$, suggested that these precursors also carried $\mathrm{PC}$ as a PTM, placental extracts were submitted to preparative reverse-phase HPLC and the resulting fractions subjected to SDS-PAGE and anti-PC immunoblotting (Fig. 3). It is clear from the multiple bands resulting from this experiment that placental extracts contain a large number of polypeptides and proteins that have PC attached. Assaying the same HPLC fractions with the specific two-site assays indicated that all the placental polypeptide precursors measured, including most processed intermediates had PC attached as indicated by a high degree of coincidence of immunoreactive peaks in peptide/peptide versus peptide/PC two-site assays (Fig. 4). The suggestion in Fig. 1 from the anti-PC/anti$\mathrm{PC}$ assay that some placental products contain more than one PC epitope is confirmed in Fig. 4 as shown by the greater absorbance achieved in the anti-PC/anti(pro)CRF assay of the later eluting proCRF broad peak (fractions 55-65; Fig. 4a) when compared with the anti$\mathrm{PC} / \mathrm{NKB}$ versus proNKB (fractions 54-64; Fig. 4b) where the absorbance readings across the broad peak in each assay is similar. This suggests again (Fig. 1) that proCRF contains more than one PC PTM, whereas proNKB has only one. As dimeric ( $\beta \mathrm{A}-\beta \mathrm{A})$ activin $\mathrm{A}$ (peak fraction 41 , (a)

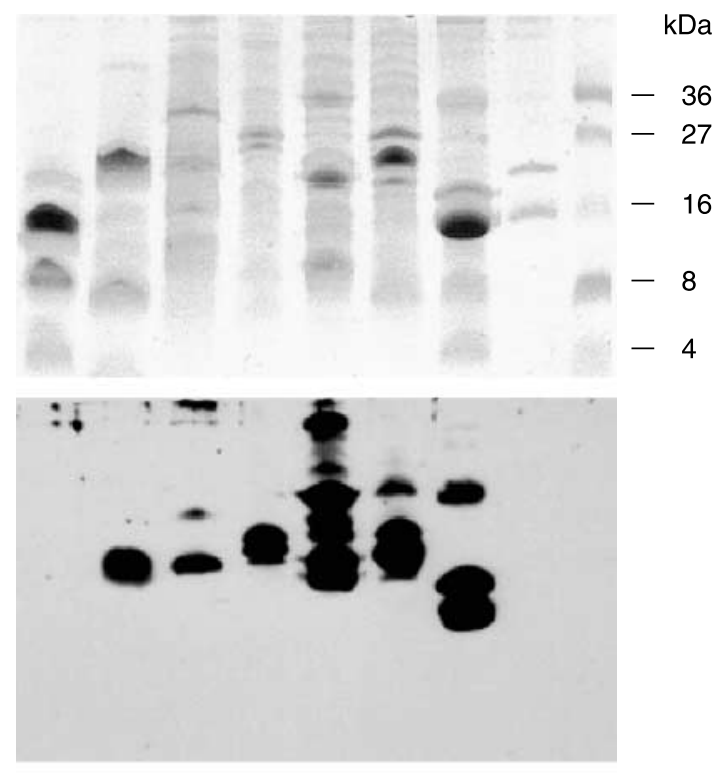

(c)

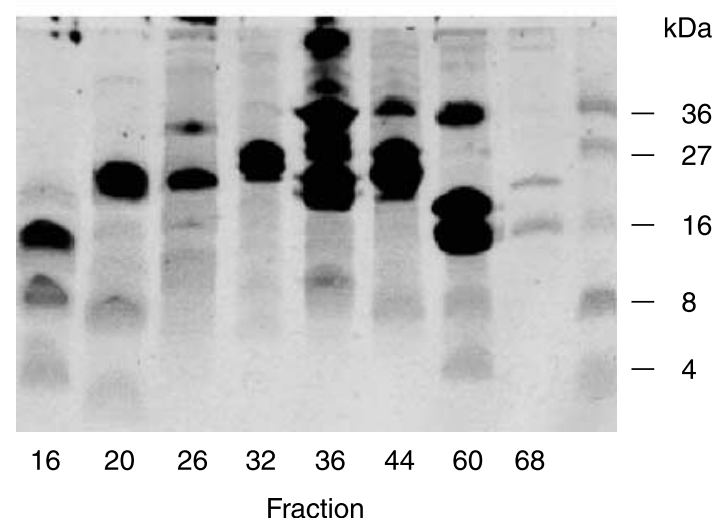

Figure 3 SDS-PAGE of selected fractions resulting from the preparative C3 HPLC of a rat placental extract. Coomassie bluestained gel is shown in (a), the anti-PC IgG western immunoblot in (b) and the merged image in (c) in which only a limited number of coomassie stained bands are PC immunoreactive.

Fig. 4c) did not coincide with any of the anti-proßA/anti$P C$ reactive peaks, this suggests that pro-activin does carry PC as a PTM but the fully processed $(\beta A-\beta A)$ placental form does not.

The first rat placental NKB peak from the C3 HPLC (fractions 33-34), which was reactive in both $\mathrm{NKB} / \mathrm{NKB}$ and PC/NKB assays, also eluted as a single peak with a Kav of 0.45 when subjected to Superdex gel filtration suggesting that it is the same as human placental NKB.

In order to investigate the mode of attachment of PC to placental prohormones we pooled fractions 40-45 and 51-55 separately and monitored the change of immunoreactivity in each pool using the proCRF, activin, PC/proCRF and PC/pro-activin two-site immunoassays after digestion with endoglycosidase or PLC. 

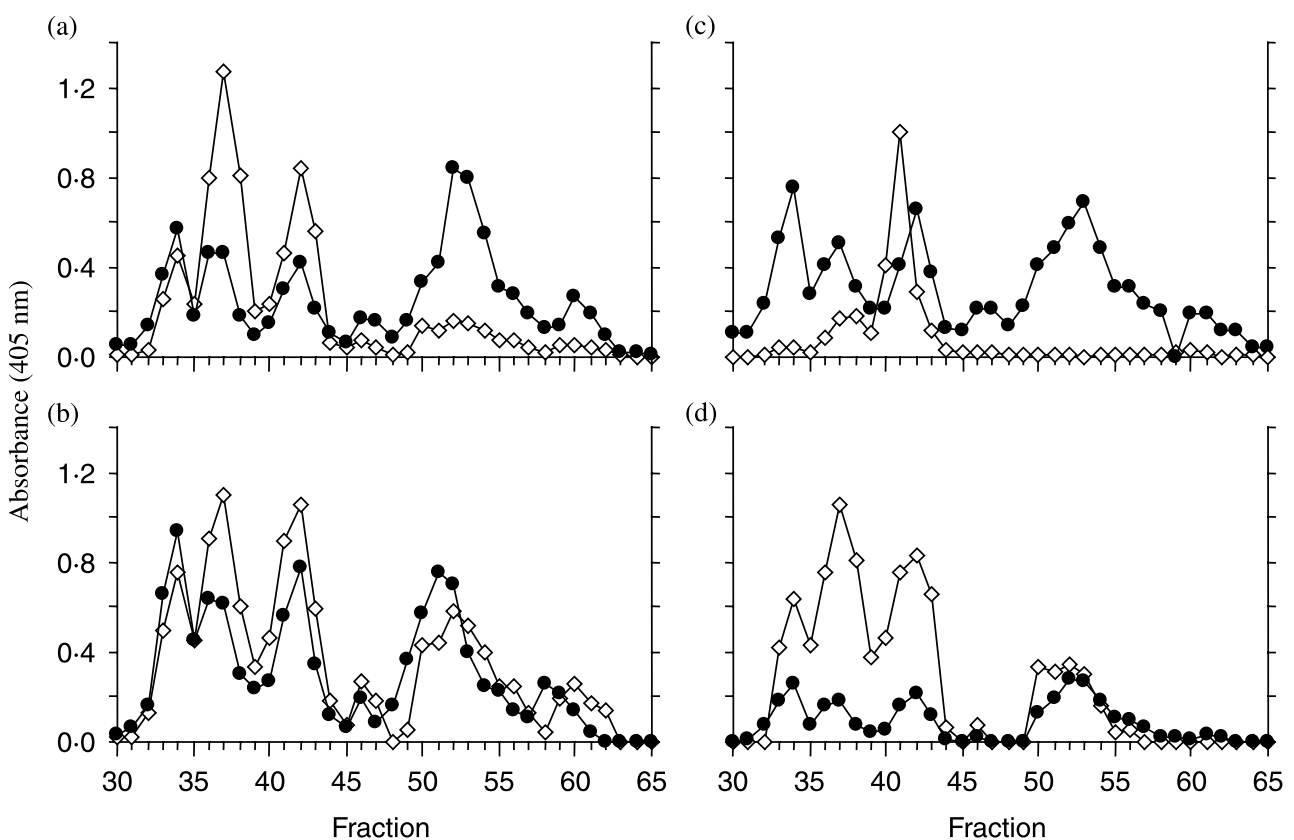

Figure 4 Comparison of PC containing neuropeptide with neuropeptide immunoreactivity in fractions from the HPLC of the rat placental extract. Fractions 30-65 from the preparative HPLC step in Fig. 3 were submitted to a number of two-site ELISAs. $-\diamond-$ represents two-site anti-neuropeptide/anti-neuropeptide assay results in each case. All ELISA protocols were the same as described in Materials and methods; (a) proCRF, in (b) NKB, in (c) activin A and (d) hemokinin. - - represents the results of two-site immunometric assays with the anti-neuropeptide antibody being in (a) anti-proCRF (1-21) IgG, (b) anti-NKB(1-5) IgG, (c) anti-pro $\beta A$ subunit $\lg G$ and (d) anti-HK(1-5) IgG in combination with anti-PC IgG in each case.

Interestingly, we detected a significant increase in immunoreactivity in both proCRF/CRF and $\mathrm{PC} /$ proCRF immunometric assays signal after deglycosylation (Fig. 5). Given the previous evidence for reduced binding seen in the anti-proCRF and anti-PC tracks of the $30 \mathrm{kDa}$ band (Fig. 2b), the increase in immunoreactivity was not unexpected and confirmed that removal of the bulky polysaccharide PTM(s) from proCRF would allow antibodies (raised originally against a short synthetic proCRF peptide or PC coupled to carrier proteins) better access to their respective epitopes in the precursor proCRF backbone. However, there was a very significant reduction in signal after PLC digestion of both pools as measured by the proCRF/PC and $\beta$ A subunit/PC two-site assays. There did not appear to be any interference of contaminating protease activity resulting from any of these enzyme digestions given the absence of any loss of immnuoreactivity in the antiproCRF/CRF and anti-activin $\mathrm{A}(\beta \mathrm{A}-\beta \mathrm{A})$ results versus controls.

\section{Discussion}

It is known that the PC group found on the filarial nematode secretory protein ES-62 is attached to the
$\mathrm{N}-\mathrm{N}$-acetyl glucosamine at the end of a complex N-linked polysaccharide moiety PTM (Haslam et al. 1997); thus, the specific mode of attachment of PC to placental polypeptide hormones will require further examination. However, the literature may provide some clues as to the identity of the enzyme involved. CTP:PC cytidylyltransferase $\alpha$ is a ubiquitous enzyme, it has a nuclear transfer signal motif and catalyses the rate-limiting step during the introduction of PC into phosphatidylcholine during membrane formation in all cells throughout the body. A second PC transferase gene, however, was discovered in 1998 (CTP:PC cytidylyltransferase $\beta$ (Lykidis et al. 1998)). It predicts an enzyme with a similar catalytic motif but lacks the nuclear transfer motif and seems to be associated with the endoplasmic reticulum (Lykidis et al. 1998), the site of translation and synthesis of proteins destined for secretion. Interestingly, this enzyme is strongly expressed in the placenta, and to some extent in the testis, with little expression in all other tissues examined (Lykidis et al. 1998, 1999), and thus is a prime candidate to play a role in PC modification of placental secretory peptides and proteins. The placenta and testis are similar in that they are both immune-privileged sites. This is biologically necessary for the success of pregnancy and to protect germ cells from autoimmune attack. In immune-privileged sites the systemic immune apparatus 
$\square$ No enzyme - Phospholipase C $\square$ Endoglycosidase
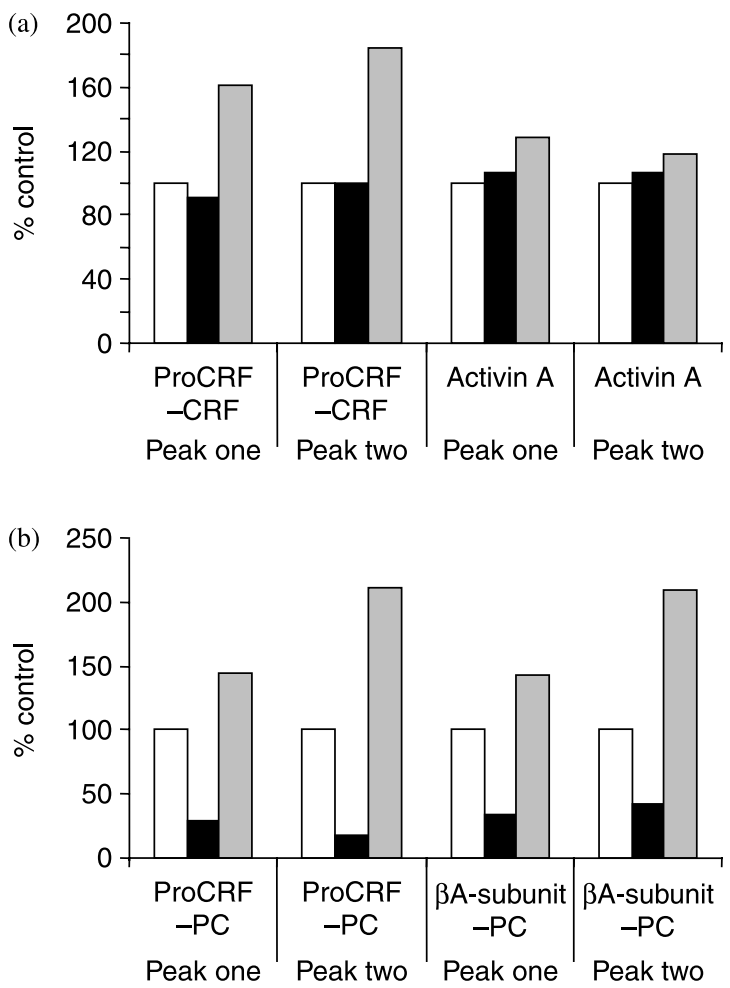

Figure 5 The effect of enzyme treatment on the immunoreactivity of pro-CRF-PC and pro- $\beta$ A-PC. Peak one represents a pool of fractions 36-37 and peak two, a pool of fractions 41-43 from Fig. 4, which were freeze-dried separately before being reconstituted in assay buffer. Open histogram represents ELISA assay result with no enzyme treatment, black histogram after phospholipase $\mathrm{C}$ digestion and grey histogram after endoglycosidase digestion. Values are the means of duplicate determinations in the respective two-site immunometric assay.

can recognise antigens, however, an immune tolerant environment is maintained. The close association between the steroidogenic (testosterone secreting) Leydig cells and interstitial testicular macrophages suggests that these cells are functionally related (Hales 2002).

From the results presented in this study, it would appear that a large number of the polypeptides and proteins synthesised by the placenta carry $\mathrm{PC}$ as a tissuespecific PTM. In placental NKB, the PC would appear to be attached via the aspartate side chain at position 4 . However, despite many repeated experiments, we have been unable to obtain any unequivocal mass spectrometric analysis with either rat or human purified placental NKB. This is due to the miniscule amount of stored mature NKB in the placenta and the fact that it has been found that mass spectrometric analysis of PC-substituent peptides are hampered by this zwitterionic group resulting in low sensitivity and unusual fragmentation ions apart from the final products, choline and PC (Grabitzki et al. 2005). The observations that PC attached to placental NKB only causes a small decrease in Kav during gel filtration, PC-proCRF has a relatively small molecular weight $(15 \mathrm{kDa})$ and endoglycosidase treatment of glycosylated PC-proCRF does not remove the PC, would suggest that the mode of attachment in the placenta is more simple than that seen in the large polysaccharide complex of ES62. Given the phospholipase lability of PCattached to placental peptides and the strong expression in the placenta of the CTP:PC cytidylyltransferase, we would speculate that $\mathrm{PC}$ is attached to NKB and proCRF (and by analogy other placental peptide hormones) via a short linker such as glycerol (cf. phosphatidyl choline and platelet activating factor). Alternatively PC could be attached directly via a high-energy labile mixed anhydride to the side chain of aspartyl residues or via ester bonds to hydroxyl side chains. However, the latter are not present in mature NKB.

The presence of PC groups on placental secretory proteins and peptides could therefore play a major role, at low concentrations, in modulating the maternal immune system (as in the case of parasitic nematode infection (Harnett et al. 2003)) and assisting in the evasion of the mother's immune surveillance. Miller et al. (1991) hypothesised that as ES-62 promoted parasitic survival by stimulating the secretion of antibodies which did not damage the adult helminth. This function of PC coupled to placental proteins (secreted or exposed at the placental/uterine interface) may also reduce antiplacental-directed antibody production. Additionally as the phosphocholinated filarial parasitic protein (ES-62) at high concentrations $(>20 \mathrm{mg} / \mathrm{ml})$ is mitogenic for B-cells in vitro (Harnett \& Harnett 1993), the increasing concentrations of placental PC-containing polypeptides in maternal blood towards term might be expected to lead to a similar increase in B-cell activity. If there is such an increase in the blood concentrations of the repertoire of maternal protective antibodies during the third trimester then it would help their placental transfer through the placental syncytiotrophoblast (Leach et al. 1996) via fetal Fc receptor, a key process necessary for neonatal immunity (Simister 2003).

The PC moieties present on many placental polypeptide hormones as seen in the many immunreactive bands in Fig. 3 may be attached to the peptide backbone such that the normally PC-unmodified (immunoreactive) epitopes that take part in currently available immunoassays designed to detect the normal peripheral and brain final processed forms are rendered non-reactive by this highly charged group. This has been found to be the case with placental NKB, as we have observed that the final placental processed form (unlike brain/synthetic NKB) cross-reacts weakly with several in-house and 
commercial NKB antisera but does cross-react with the anti-PC antibody. Since our original report suggesting that many of the symptoms of pre-eclampsia could be explained by progressive stimulation of the three neurokinin receptors by increasing secretion of NKB by the placenta (Page et al. 2000); lung and liver oedema (Grant et al. 2002) and a decrease in placental antioxidant defences (Sawicki et al. 2003) have been added to the list of NKBinduced conditions. The effect of this highly charged PC group on the biological activity of NKB at neurokinin (NK3R) and other receptors (e.g. the PC-platelet activating factor receptor and PC-inflammatory receptors) during pregnancy particularly in the pathogenesis of pre-eclampsia must await complete characterisation and synthesis of placental phosphocholinated NKB. However, if PC-NKB does have potent activity at the NK3R, it may explain why senktide, a synthetic neurokinin analogue, has been used in NK3 receptor agonist studies rather than the synthetic brain form of $\mathrm{NKB}$, which is a relatively poor/partial agonist at its 'preferred receptor' (NK3R) found predominantly in the periphery (Wormser et al. 1986).

This study is the first to identify proCRF and its mature peptide in the rat placenta. Although our results indicate that in the rat, placental CRF remains predominantly unprocessed as a phosphocholinated precursor proCRF and its glycosylated forms, some processing does occur as demonstrated by the $4.5 \mathrm{kDa}$ band (the size of mature CRF) seen in the anti-CRF track (Fig. 2) and is free of PC-immunoreactivity. The placental extract immunoblots probed with anti-CRF, anti-proCRF and anti-PC antibodies all demonstrate a number of intermediate processed forms, suggesting that the placenta contains endopeptidases capable of processing proCRF. As our rat placental tissue extractions were carried out rapidly at strong acidic $\mathrm{pH}$, minimal protein degradation would be expected, suggesting these intermediate forms are not a consequence of adventitious degradation during tissue processing. The difference in the size and band intensity of the proteins will reflect not only the differential processing of the proCRF precursor but also the varying number PC-PTMs and the size and complexity of sugars moieties at $\mathrm{N}$-linked glycosylation sites and their proximity to the anti-proCRF and anti-PC epitopes. Increased processing of proCRF has, however, been demonstrated in pre-eclampsia placentae when compared with normal term placentae (Ahmed et al. 2000) and was hypothesised to be related to damage in vivo associated with preeclampsia placental pathology.

After demonstrating that the rat placenta contained substantial amounts of proCRF, we explored whether these forms are secreted and circulate in the maternal blood and have demonstrated that CRF is present in rat pregnancy plasma, although it appears mainly present as phosphocholinated proCRF and its glycosylated forms suggesting the precursors are the dominant circulating forms during pregnancy in the rat. In the human, although there is evidence for unprocessed proCRF in early pregnancy it is mainly fully processed to mature CRF towards term (Sanderson et al. 2000). The low signal seen in Fig. $1 a$ with human-term placental extracts in the proCRF/CRF two-site assay is in agreement with this. It is interesting to note that more heterogeneity was evident in the immunoblots of rat placental extracts than in the secreted forms found in plasma suggesting maturation, $\mathrm{PC}$ and polysaccharide addition are late events during processing within the placenta. The fact that the processed forms of proCRF in the plasma contain PC as a PTM suggests that PC plays an important function during pregnancy and may be the reason for the elevated levels of C-reactive protein (Tjoa 2003) and the accompanying inflammation seen in this condition (Redman et al. 1999). Additionally, once the behaviour of this PTM has affected the immunological detection and biological activity of a variety of placental polypeptide hormones has been revealed, increased recognition of its presence and role played when attached to each placental hormone may lead to a new era of placental physiology/pathology.

There are perhaps other situations in which PC-containing proteins take part in physiology and disease. It may be no coincidence that, whereas CTP:PC cytidylyltransferase- $\beta$ expression is very low in most peripheral tissues, it could be easily detected in the cytoplasm of HeLa cells (Lykidis et al. 1998). Downregulation of the immune system is an important step during the genesis of some tumours; thus the detection of tumour cell-surface/secretory proteins could be useful in early cancer diagnosis and inhibiting the enzyme(s) involved in PC attachment to proteins could form part of tumour therapy.

Another important area in which PC may play a role is arthritis, as recently it has been demonstrated that administration of the filarial nematode secretory glycoprotein ES-62 can reverse the experimentally induced condition in mice (McInnes et al. 2003). Thus, the possibility that the remission of rheumatoid arthritis often seen in pregnancy may be due to the effects of some circulating placental PC-containing peptides, suggests that the use of simple PC-peptidelike compounds should be considered for treating this condition. Similar compounds could also be used to stop recurring miscarriage when it is a consequence of enhanced immune intolerance during early pregnancy.

Finally, if tissue expression of PC proteins allows placental survival then engineering stem cells destined for transplant therapy to express this property may constitute a universal transplant strategy. 


\section{Acknowledgements}

We thank Prof. Philip Knight of the University of Reading for kindly providing anti-inhibin/activin $\beta A$-subunit antibodies.

\section{Funding}

This study was funded by the MRC. The authors declare that there is no conflict of interest that would prejudice this manuscripts impartiality.

\section{References}

Ahmed I, Glynn BP, Perkins AV, Castro MG, Rowe J, Morrison E \& Linton EA 2000 Processing of procorticotropin-releasing hormone (Pro-CRH): molecular forms of CRH in normal and preeclamptic pregnancy. Journal of Clinical Endocrinology and Metabolism 85 $755-764$.

Brody S \& Carlstrom G 1962 Immuno-assay of human chorionic gonadotropin in normal and pathologic pregnancy. Journal of Clinical Endocrinology and Metabolism 22 564-574.

Campbell EA, Linton EA, Wolfe CD, Scraggs PR, Jones MT \& Lowry PJ 1987 Plasma corticotropin-releasing hormone concentrations during pregnancy and parturition. Journal of Clinical Endocrinology and Metabolism 64 1054-1059.

Florio P, Imperatore A, Sanseverino F, Torricelli M, Reis FM, Lowry PJ \& Petraglia F 2004 The measurement of maternal plasma corticotropin-releasing factor (CRF) and CRF-binding protein improves the early prediction of preeclampsia. Journal of Clinical Endocrinology and Metabolism 89 4673-4677.

Grabitzki J, Sauerland V, Geyer R \& Lochnit G 2005 Identification of phophorylcholine substituted peptides by their characteristic mass spectrometric fragmentation. European Journal of Mass Spectrometry 11 335-344.

Grant AD, Akhtar R, Gerard NP \& Brain SD 2002 Neurokinin B induces oedema formation in mouse lung via tachykinin receptorindependent mechanisms. Journal of Physiology 543 1007-1014.

Hales DB 2002 Testicular macrophage modulation of Leydig cell steroidogenesis. Journal of Reproductive Immunology 57 3-18.

Harnett W \& Harnett MM 1993 Inhibition of murine B cell proliferation and down-regulation of protein kinase $\mathrm{C}$ levels by a phosphocholine-containing filarial excretory production. Journal of Immunology 151 4829-4837.

Harnett W, Harnett MM \& Byron O 2003 Structural/functional aspects of ES-62- a secreted immunomodulatory phosphorylcholine containing filarial nematode glycoprotein. Current Protein and Peptide Science 4 59-72.

Haslam SM, Khoo KH, Houston KM, Harnett W, Morris HR \& Dell A 1997 Characterisation of the phosphorylcholine-containing $\mathrm{N}$-linked oligosaccharides in the excretory-secretory $62 \mathrm{kDa}$ glycoprotein of Acanthocheilonema viteae. Molecular and Biochemical Parasitology 855366.

Kaplan SL, Gurpide E, Sciarra JJ \& Grumbach MM 1968 Metabolic clearance rate and production rate of chorionic growth hormoneprolactin in late pregnancy. Journal of Clinical Endocrinology and Metabolism 28 1450-1460.

Knight PG, Muttukrishna S \& Groome NP 1996 Development and application of a two-site enzyme immunoassay for the determination of 'total' activin-A concentrations in serum and follicular fluid. Journal of Endocrinology 148 267-279.

Krieger DT 1982 Placenta as a source of 'brain' and 'pituitary' hormones. Biology of Reproduction 26 55-71.
Leach JL, Sedmak DD, Osborne JM, Rahill B, Lairmore MD \& Anderson CL 1996 Isolation form human placenta of the IgG transporter, FcRn, and localization to the syncytiotrophoblast: implications for maternal-fetal antibody transport. Journal of Immunology 157 3317-3322.

Liwski R, Zhou J, McAlister V \& Lee TD 2000 Prolongation of allograph survival by Nippostronglus brasilensis is associated with decreased allospecific cytotoxic T lymphocyte activity and development of T cytotoxic cell type 2 cells. Transplantation 69 1912-1922.

Lykidis A, Murti KG \& Jackowski S 1998 Cloning and characterization of a second human CTP: phosphocholine cytidylyltransferase. Journal of Biological Chemistry 273 14022-14029.

Lykidis A, Baburina I \& Jackowski S 1999 Distribution of CTP:phosphocholine cytidylyltransferase (CCT) isoforms. Journal of Biological Chemistry 274 26992-27001.

McInnes IB, Leung BP, Harnett M, Gracie JA, Liew FY \& Harnett W 2003 A novel therapeutic approach targeting articular inflammation using the filarial nematode-derived phosphorylcholinecontaining glycoprotein ES-62. Journal of Immunology 171 2127-2133.

McLean M, Bisits A, Davies J, Woods R, Lowry P \& Smith R 1995 A placental clock controlling the length of human pregnancy. Nature Medicine 1 460-463.

Miller S, Schreuer D \& Hammerberg B 1991 Inhibition of antigendriven proliferative response and enhancement of antibody production during infection with Brugia pahangi. Journal of Immunology 147 1007-1013.

Page NM, Woods RJ, Gardiner SM, Lomthaisong K, Gladwell RT, Butlin DJ, Manyonda IT \& Lowry PJ 2000 Excessive placental secretion of neurokinin B during the third trimester causes preeclampsia. Nature 405 797-800.

Redman CW, Sacks GP \& Sargent IL 1999 Preeclampsia: an excessive maternal inflammatory response to pregnancy. American Journal of Obstetrics and Gynecology 180 499-506.

Robinson BG, Arbister JL, Emanuel RL \& Majzoub JA 1989 Species specific placental corticotrophin releasing hormone messenger RNA and peptide expression. Molecular and Cellular Endocrinology 62 337-341.

Sanderson TC, Woods RJ, Kemp CF \& Lowry PJ 2000 Detection of $\mathrm{N}$-terminal pro-corticotrophin releasing hormone (CRH) and a 'Novel' CRH in human maternal plasma and placenta. Placenta 21 218-225.

Sawicki G, Dakour J \& Morrish DW 2003 Functional proteomics of neurokinin $\mathrm{B}$ in the placenta indicates a novel role in regulating cytotrophoblast antioxidant defences. Proteomics 3 2044-2051.

Saxena BN, Refetoff S, Emerson K \& Selenkow HA 1968 A rapid radioimmunoassay for human placental lactogen, Application to normal and pathologic pregnancies. American Journal of Obstetrics and Gynaecology 101 874-885.

Simister NE 2003 Placental transport of immunoglobulin G. Vaccine 21 $3365-3369$.

Tjoa ML 2003 Elevated C-reactive protein levels during first trimester of pregnancy are indicative of preeclampsia and intrauterine growth restriction. Journal of Reproductive Immunology 59 29-37.

Vance DE 1990 Boehringer Mannheim Award lecture. Phosphatidylcholine metabolism: masochistic enzymology, metabolic regulation, and lipoprotein assembly. Biochemistry and Cell Biology 68 1151-1165.

Wormser U, Laufer R, Hart Y, Chorev M, Gilon C \& Selinger Z 1986 Highly selective agonists for substance $\mathrm{P}$ receptor subtypes. EMBO Journal 5 2805-2808.

Received in final form 25 May 2007

Accepted 24 July 2007

Made available online as an Accepted Preprint 24 July 2007 